Volume 9. No. 8, August 2021

International Journal of Emerging Trends in Engineering Research

Available Online at http://www.warse.org/IJETER/static/pdf/file/ijeter28982021.pdf

https://doi.org/10.30534/ijeter/2021/28982021

\title{
Assessment on Performance advancement utilizing nanofluid as additional fluid in a Refrigeration System
}

\author{
J. Anandakumar ${ }^{1}$, Dr. K. Palaniradja ${ }^{2}$ \\ ${ }^{1}$ Research Scholar, Department of Mechanical Engineering, Pondicherry Engineering College, Pillaichavadi, \\ Puducherry - 605014, India, anandakumar850@gmail.com \\ ${ }^{2}$ Professor, Department of Mechanical Engineering, Pondicherry Engineering College, Pillaichavadi, Puducherry \\ - 605014, India
}

\begin{abstract}
The performance of the refrigeration machine needs to be increased, which usually may be carried out by changing the unit or the properties of primary and additional working fluids. Currently, nanofluids or hybrid nanofluids possess obtained curiosity in various engineering areas scheduled to it has the superb thermophysical properties, which will be quickly applied in refrigeration equipment by various functions for overall performance improvement. This paper assesses and then summarizes the latest research carried out on the consumption of nanofluids in the refrigeration machine as the supplementary liquid is mentioned. At last, the difficulties and possibilities for upcoming study are determined, which will be beneficial for the beginners and then concerns in this discipline.
\end{abstract}

Key words: Nanofluids, refrigeration, performance, equipment.

\section{INTRODUCTION}

Nanofluids will be broadly utilized in various engineering uses, for example, uses in the chemical type group, refrigeration, and air conditioning, etc. Currently, huge selling prices of energy sources inspire the sector to make use of energy-saving strategies as very much as feasible in their services. For years, initiatives possess have been produced to increase the heat transfer of heat exchangers, decrease the heat transfer period, and then at last increase energy source usage performance. Even though necessary to the restriction of energy assets the studies are carried out in the area of increasing the effectiveness and overall performance of thermal devices. It may become attained by first of all increasing the layout of device parts generally heat exchangers and then subsequently carrying out adjustments in the category of functioning liquids. In other circumstances i.e. intended for an innovative category of functioning liquid, following various choices of experiments, the idea is discovered that may a unique type of liquid regarded as nanofluid reveals greater effects by increasing the total performance of devices.

In the option to nanofluids, lately, cross types nanofluids possess as well obtained focus as a large improvement of heat transfer characteristics may be credited to the synergistic impact induced by hybridization [1]. Nanofluids may perform some distinct functions for overall performance betterment of refrigeration (i) Refrigerant depending on nanofluids (ii) Lubricant depending on nanofluids and (iii) supplementary fluid depending on nanofluids.

Alawi et al. [2] worked on an assessment to observe the impact of applying nano refrigerant in heat transfer efficiency and energy levels usage of chilling equipment. Nair et al. [3] worked on an extensive assessment on recent, present, and upcoming from nano refrigerants which usually consist of their particular planning, thermophysical properties, heat transfer, and pressure drop characteristics, and overall performance of refrigeration devices even though applying nano refrigerants. Redhwanet al. [4] likewise considered the total performance of numerous choices of refrigerants depending on nano refrigerants.

Azmi et al. [5] worked on an assessment on energy source keeping in the refrigeration device employing nano refrigerant and nano lubricant. It may become noticed that they released assessment functions primarily focused on nano refrigerants and then nano lubricants; even so, by way of the greatest of the author's expertise, no assessment has been lately carried out on nanofluids as supplementary functioning chemicals used for refrigeration. Further, besides density, heat capability, and thermal conductivity, additional characteristics possess not come assessed.

In this paper, the study works about the uses of nanofluids in refrigeration intended for increasing overall performance have been examined. The preparation and portrayal of nanofluids will be described. Apart from viscosity, thermal conductivity, density \& specific heat, several additional significant properties just like surface tension, at last, finishing statements and upcoming scopes will be presented. 


\section{PREPARATION AND CHARACTERIZATION}

The primary and then generally essential stage in the review of the nanofluids is usually had the preparation method because it influences the stableness and then characteristics of nanofluids. The preparation in nanofluids needs a few unique techniques for consistent and steady alternatives and much less cohesion and sedimentation challenges. Nanofluids which usually may be utilized for supplementary liquids in the refrigeration machine is developed by dispersing metallic, metal oxides, non-metals of nano-size in the base liquids many of these as normal water and brine. Normal water and brine-based nanofluid preparation have been described by various creators such as $[1,7]$. Presently there are primarily two strategies for the preparation of nanofluids: single-step technique and two-step technique.

These may be carried out simply by using the chemical type technique or mechanized options. Regarding the single-step approach, nanoparticles are going to be developed and then passed out in liquids simultaneously. In the two-step, approach nanoparticles are produced individually and after that spread that keeping the stableness of nanofluid. Fig. 1 presents a flowchart for manufacturing nanofluid.
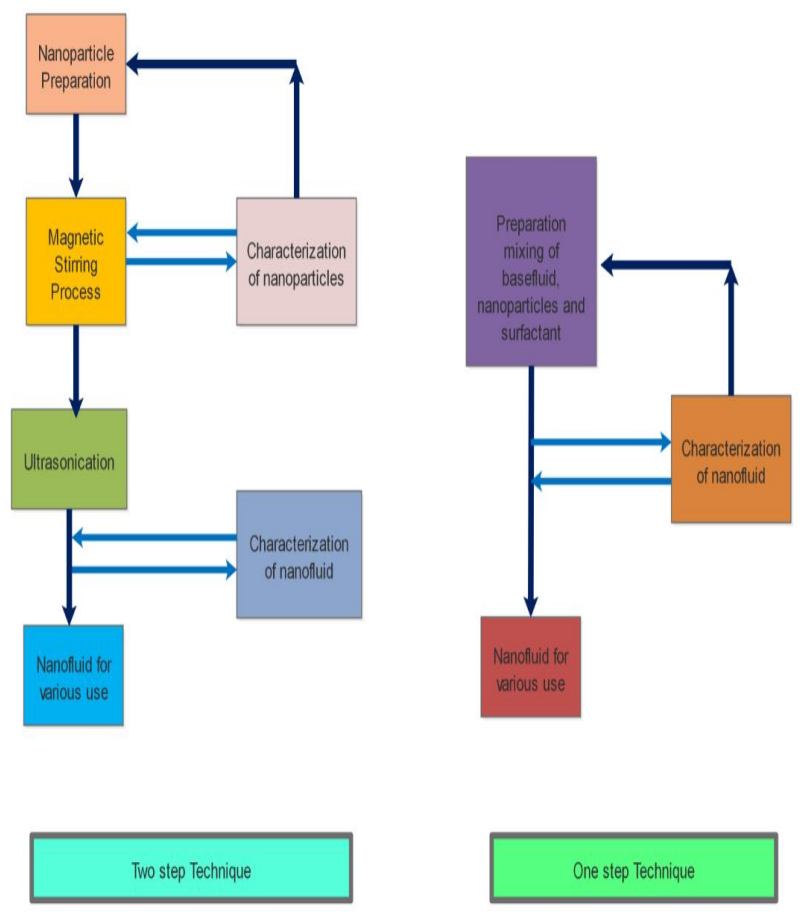

Fig.1. A flowchart for manufacturing nanofluid.

The two-step technique is favored more than the single-step technique. The preparation concerning oil-based nanofluids which usually might be a feasible applicant in refrigerator compressors provides lately been also very well described by various study reports [5]. The characterization of nanofluids comprises of (i) the structural characteristics of nanoparticles to approximate the chemical substance characteristics, proportions, and morphology as perfectly as the proportions of agglomerations, and then (ii) dispersal stableness evaluation of nanofluids. Nanoparticle portrayal methods consist of transmission electron microscopy, UV-Vis spectroscopy, etc. [6].

\section{PROPERTIES OF NANOFLUID}

\subsection{Thermal conductivity}

Thermal conductivity is special between the important features of nanofluids for increasing the heat transfer capabilities. The heat transfer coefficient and then heat transfer quantity is hugely based upon thermal conductivity. It is the well-established point that may the thermal conductivity raises by way of working with nanofluids and so it is based upon various guidelines consisting of volume level portion, heat range, compound proportions, compound appearance, $\mathrm{pH}$ amount, additive, and processing technique.

\subsection{Viscosity}

Viscosity is one of the significant thermophysical characteristics which will impact equally heat transmission pressure drop of nanofluid. By way of the boost in dynamic viscosity, the convective heat transfer coefficient decreases, and the frictional pressure drop, and therefore pumping ability raises. Research on water/brine and then lubrication-based nanofluids have come evaluated by various experts.

\subsection{Specific temperature and density}

Specific temperature and density extremely affect the heat transfer characteristics of nanofluid. Towards basic, specific heat lowers and density raises by the option of nanoparticles in basic liquid.

\subsection{Surface tension}

Surface tension is an essential premise of nanofluid although considering the movement, bubble creation, dry out and so heat transfer properties in very hot. The extremely small study provides been lately carried out upon the surface area tension of nanofluids.

\section{EFFICIENCY INCREASE EMPLOYING NANOFLUIDS AS SUPPLEMENTARY FLUID}

Heat transfer may be improved by raising that heat transfer coefficient. It has been identified that pressure drop \& heat transfer equally grow, although the boost in pressure drop is minimal as examined to heat transfer improvement. Most research has been carried out by way of several experts when it comes to the concentration of heat exchangers credited to 
restriction of space and specifications, saving of energy source, saving of elements, quickly managing the device and variables, greater heat transfer efficiency. Tube-in-tube, shell-tube as well as, plate heat exchangers are completely employed as a condenser and evaporator designed for liquids supplementary essential fluids. Even so, the plate heat exchanger may be extra more suitable intended for differing chilling plenty.

Nanofluids can is utilized because of supplementary liquids in equal evaporator and condenser attributes [7]. In the vapour compression refrigeration system, the thermal level of resistance of single-phase supplementary fluid is substantially additional than that of refrigerant in an equally evaporator and condenser. Therefore, the efficiency of the condenser or evaporator is even more very sensitive to the supplementary fluid heat transfer attribute, which provides a superb chance to make use of nanofluid as a supplementary refrigerant or coolant in the refrigeration machine.

\subsection{Nanofluids employed in condenser side}

Nanofluid may be efficiently utilized because of coolant in condenser or gas cooler to the chilling tower system. Loaiza et al. [8] numerically analyzed the usage of nanofluid just as an additional coolant in vapour compression refrigeration devices. It has been lately discovered that employing nanofluids as the supplementary coolant, for provided refrigerating capability, evaporator region, and refrigerant difficulty drop will be decreased with lower in nanoparticle proportions and rise in its focus. As well, nanofluid aspect pressure drops and using a pump power rise by way of nanoparticle volume portion and reduce with nanoparticle proportions.

The efficiency studies of the nanofluid chilled shell and pipe gas much cooler in the transcritical $\mathrm{CO} 2$ refrigeration cycle possess have been done with Sarkar [9] and developments in the gas much cooler efficiency, chilling capability, and COP not having the consequence of growing power have been lately discovered.

A simulation for the utility of $\mathrm{Cu}-\mathrm{H} 2 \mathrm{O}$ nanofluid as a condenser coolant in a vapour compression heating pump has been lately done by Parise and Teacher. [10] and a 5.4\% rise in $\mathrm{COP}$ was first expected for a nanoparticle quantity fraction of $2 \%$. the vapour compression refrigeration system employing R134a refrigerant in the primary loop and nanofluid in the secondary loop and observed $17 \%$ to $20 \%$ performance enhancement for the same geometrical parameters, system. The theoretical efficiency studies of the nanofluid cooled down dual-pipe gas cooler in the transcritical $\mathrm{CO} 2$ refrigeration cycle possess been lately carried out by Sarkar [11] and advancement in the electricity much cooler performance, chilling capability and COP not having the moving power possess been discovered.

Maximum COP improvement of $26 \%$ has been lately acquired by employing $\mathrm{Al}_{2} \mathrm{O}_{3} / \mathrm{H}_{2} \mathrm{O}$ nanofluid as a coolant. Experimental analysis on the energy efficiency of the wet chilling system by way of the counter-top circulation set up just by using multi-walled carbon nano pipes and Nanoporous graphene nanofluids possess been lately taken out by Askari et al. [12].

They will notice the rise in chilling tower system performance and chilling vary as very well coolant utilization. Therefore, equally the lengths and widths of the condenser and then chilling tower system may be decreased by employing nanofluids. the total performance of dual tube gas cooler for trans-critical refrigeration schedule employing nanofluid and normal water as a coolant. Impact of several overall performance variables just like Reynolds number, gas cooler pressure, using a pump power, and quantity attention in $\mathrm{COP}$ and performance of refrigeration device has been researched for turbulent circulation. Intended for consistent Reynolds number alumina nano substance provides excellent efficiency as a coolant however, for exact growing power normal water works as an enhanced coolant.

\subsection{Nanofluids utilized in evaporator side}

The research on the employ of nanofluids as supplementary refrigerants in the evaporator announced the rise in chilling ability, reduction in ac compressor function, and therefore enhancement in COP by applying nanofluids. Chilling capability raises generally as a consequence of the rise in the heat balance transfer coefficient Ndoye et al. [13] announced the boost in cold sequence effectiveness by employing nanofluids as supplementary refrigerants. researched analytically that energy source efficiency in supplementary pathways of refrigeration machines employing several nanofluids. It has been lately seen that pressure drop and using a pump power raises due to molecule concentration. Vasconcelos et al. [14] announced outstanding chilling capability and COP simply by employing SWCNT.

It can of that the implementation of nanofluids in the equal condenser and evaporator parts enhances the efficiency of the refrigeration device, even though the greatest efficiency may be acquired by employing maximum nanoparticle quantity attention $\mathrm{CuO}$-water nanofluid provides come utilized interior of the collector model in a tandem evaporator vapor compression stream refrigeration device by Bovagh chiet al. [15].

The employ concerning nanofluid as a supplementary refrigerant raises the chilling capability, coefficient of performance, and heat transfer characteristics by way of a minimal rise in using a pump power. It likewise decreases the usage and price of the main refrigerant. Once nanoparticles 
J. Anandakumar et al., International Journal of Emerging Trends in Engineering Research, 9(8), August 2021, 1205 - 1210

will be utilized in the snow development approach, it raises the supercooling level which usually helps prevent the adhesion of ice cubes on chilling wall space and likewise raises the nucleation level. This increases the total performance of ice-producing models. Working with nanofluid by way of altered container style rather than classic dairy dispenser enhances foodstuff safety and then will save energy usage. Due to positive aspects in conditions of efficiency improvement of refrigeration device, the nanofluid founds its component in vapour compression schedule and refrigeration plants of chilly sequence, chilling tower system, food control devices, grocery stores, tube heat exchangers, etc. as a supplementary coolant in evaporator and condenser part. Table 1 summarizes the research on the application of nanofluid as additional fluid in a Refrigeration System by reducing condenser heat being rejected and compressor work as well as consequently raises the coefficient of performance.

Table.1. The concentration of different Nanoparticles and Operating Conditions

\begin{tabular}{|c|c|c|c|}
\hline Researcher & Nanofluids & Operating Conditions & Evaluations \\
\hline Anbu [16] & $\mathrm{TiO} 2 / \mathrm{DI}$ & $\begin{array}{l}\text { The research is carried } \\
\text { out with turbulent flow } \\
\text { and } \Phi=0.25 \text { and } 0.5 \mathrm{v} \% \text {. }\end{array}$ & $\begin{array}{l}\text { The thermal conductivity and viscosity of TiO2/DI } \\
\text { water nanofluids are calculated for volume } \\
\text { concentrations of } 0.25 \text { and } 0.5 \% \text {. The } \\
\text { improvement in thermal conductivities is } 4.91 \text { and } \\
7.21 \% \text {, correspondingly, when compared to DI } \\
\text { water. }\end{array}$ \\
\hline Rehman [17] & $\begin{array}{l}\text { MWCNTs and } \\
\text { Eco-Friendly } \\
\text { Jatropha Seed } \\
\text { Oil-based Nanofluid. }\end{array}$ & $\begin{array}{c}\text { The range of } 25-65{ }^{\circ} \mathrm{C} \\
\text { and nanoparticle weight } \\
\text { fraction in the range of } \\
0.2-0.8 \mathrm{wt} . \%\end{array}$ & $\begin{array}{l}\text { The outcomes revealed the excellent MWCNT's } \\
\text { dispersal solidity in Jatropha seed oil and thermal } \\
\text { conductivity improvement from } 2.29 \% \text { to } 6.76 \% \text {. }\end{array}$ \\
\hline Asadi [18] & $\begin{array}{l}\text { MgO-MWCNT/ } \\
\text { thermal oil hybrid } \\
\text { nanofluid. }\end{array}$ & $\begin{array}{l}\text { Temperatures }\left(25^{\circ} \mathrm{C} \text { to }\right. \\
\left.50^{\circ} \mathrm{C}\right) \text { and solid } \\
\text { concentrations }(0.25 \% \text { to } \\
2 \%)\end{array}$ & $\begin{array}{l}\text { The highest improvement is required to place at a } \\
\text { temperature of } 50^{\circ} \mathrm{C} \text { and a solid quantity of } 2 \% \text { by } \\
65 \% \text {. Dependent on the experimental } \\
\text { measurement, a new very accurate correlation to } \\
\text { forecast the thermal conductivity of the nanofluid } \\
\text { has been introduced in the analyzed range of } \\
\text { temperatures and solid levels. }\end{array}$ \\
\hline Arya [19] & $\mathrm{MgO} /$ ethylene glycol & $\begin{array}{c}\text { Different weight } \\
\text { concentrations of } 0.1 \% \text {, } \\
0.2 \% \text { and } 0.3 \%\end{array}$ & $\begin{array}{c}\text { Nanoparticles have been identified to improve the } \\
\text { pressure drop over the base fluid. The highest } \\
\text { enhancement in pressure drop was found at wt. } \%= \\
0.3 \text { by } \sim 89 \% \text {. }\end{array}$ \\
\hline Zadkhast [20] & MWCNT-CuO & $\begin{array}{l}\text { The temperature ranges } \\
\text { from } 25-50^{\circ} \mathrm{C} \text {. A hot } \\
\text { water bath is used to } \\
\text { stabilize the temperature } \\
\text { at } 25,30,35,40,45 \text {, and } \\
50^{\circ} \mathrm{C} \text { during the } \\
\text { measurements. }\end{array}$ & $\begin{array}{l}\text { The results show in which the thermal conductivity } \\
\text { of the nanofluid raises at a much more solid } \\
\text { quantity. Moreover, the thermal conductivity of the } \\
\text { nanofluid raises with the temperature; }\end{array}$ \\
\hline Kamatchi [21] & $\begin{array}{l}\text { Reduced graphene } \\
\text { oxide (rGO)/water }\end{array}$ & $\begin{array}{l}\text { Concentrations of } 0.01, \\
0.1, \text { and } 0.3 \mathrm{~g} / \mathrm{l} \text { of } \\
\mathrm{rGO} / \text { water nanofluids } \\
\text { are then prepared by an } \\
\text { ultrasonic homogenizer } \\
\text { and probe sonicator }\end{array}$ & $\begin{array}{l}\text { The thermal conductivity of the well-prepared rGO } \\
\text { nanofluids increases linearly along with levels and } \\
\text { temperature. The thermal conductivity of } 0.3 \mathrm{~g} / \mathrm{l} \text { of } \\
\text { rGO nanofluid is } 10 \% \text { greater than DI water at } \\
\qquad 75^{\circ} \mathrm{C} \text {. }\end{array}$ \\
\hline $\begin{array}{c}\text { Khoshvaght-Aliabadi } \\
\text { [22] }\end{array}$ & $\mathrm{Cu}-$ Water & weight fraction is $0.1 \%$. & $\begin{array}{l}\text { The efficiency aspects related to the simultaneous } \\
\text { application of } \mathrm{Cu} \text {-water nanofluid are considerably } \\
\text { higher than those related to the specific methods. }\end{array}$ \\
\hline Takabi [23] & $\begin{array}{c}\mathrm{A} 12 \mathrm{O} 3 / \text { water } \\
\text { nanofluid, and } \\
\mathrm{A} 12 \mathrm{O} 3-\mathrm{Cu} / \text { water } \\
\text { (Hybrid) }\end{array}$ & $\begin{array}{c}\text { Volume concentration of } \\
0 \% \leq \phi \leq 2 \%)\end{array}$ & $\begin{array}{l}\text { The hybrid nanofluid enhances the heat transfer } \\
\text { rate compared to nanofluid, which outcomes in a } \\
\text { much better cooling down the functionality of the } \\
\text { confinement and lower temperature of the warmed } \\
\text { surface area. }\end{array}$ \\
\hline
\end{tabular}




\section{CONCLUSIONS}

Finally, the development of nanofluids in the refrigeration machine in an additional fluid is evaluated in this kind of research. Preparing, portrayal, thermophysical characteristics the refrigeration machine mentioned.

The results that may become produced are when benefits:

- The thermal conductivity of nanofluid increases because of heat range and quantity level concentration. Also, it increases with minimizing element structure.

- Typically, the viscosity of nanofluid raises due to the raise of the compound quantity amount. But it reduces with a rise in temperatures. Consequently, pressure drop and friction reduction likewise reduce due to a rise in temperatures.

- supplementary fluid in the evaporator and condenser part necessary to heat transfer improvement features.

- Due to several conflicts between plenty of researcher's conclusions, presently there is an extra opportunity in the discipline of nanoscience to clears these types of worries.

\section{REFERENCES}

1. Sarkar J, Ghosh P, Adil A. A review on hybrid nanofluids: recent research, development, and applications. Renew Sustain Energy Rev 2015; 43:164-77.

2. Alawi OA, Sidik NAC, Kherbeet AS. Nanorefrigerant effects in heat transfer performance and energy consumption reduction: a review. Int Commun Heat Mass Transf 2015; 69:76-83.

3. Nair V, Tailor PR, Parekh AD. Nanorefrigerants: a comprehensive review of its past, present, and future. Int J Refrig 2016; 67:290-307.

4. Redhwan AAM, Azmi WH, Sharif MZ, Mamat R. Development of nano refrigerants for various types of refrigerant-based: a comprehensive review on performance. Int Commun Heat Mass Transf 2016; 76:285-93.

5. Azmi WH, Sharif MZ, Yusof TM, Mamat R, Redhwan AAM. Potential of nanorefrigerant and nano lubricant on energy saving in the refrigeration system - a review. Renew Sustain Energy Rev 2017; 69:415-28.

6. Devendiran DK, Amirtham VA. A review of preparation, characterization, properties, and applications of nanofluids. Renew Sustain Energy Rev 2016; 60:21-40.

7. Nitsas MT, Koronaki IP. Investigating the potential impact of nanofluids on the performance of condensers and evaporators - a general approach. Appl Therm Eng 2016; 100:577-85.

8. Loaiza, J. C. V., Pruzaesky, F. C., \& Parise, J. A. R. (2010). A numerical study on the application of nanofluids in refrigeration systems. International Refrigeration and Air Conditioning Conference, (2010).

9. Sarkar, J. (2011). Performance of nanofluid-cooled shell and tube gas cooler in transcritical $\mathrm{CO} 2$ refrigeration systems. Applied Thermal Engineering, 31(14-15), 2541-2548.

10. Parise, J. A. R. (2012). A Simulation Model for the Application of Nanofluids as Condenser Coolants in Vapor Compression Heat Pumps. International Refrigeration and Air Conditioning Conference, (2010).

11. Sarkar, J. (2015). Performance improvement of the double-tube gas cooler in the $\mathrm{CO} 2$ refrigeration system using nanofluids. Thermal Science, 19(1), 109-118.

12. Askari, S., Lotfi, R., Seifkordi, A., Rashidi, A. M., \& Koolivand, H. (2016). A novel approach for energy and water conservation in wet cooling towers by using MWNTs and nanoporous graphene nanofluids. Energy Conversion and Management, 109, 10-18.

13. Ndoye FT, Schalbart P, Leducq D, Alvarez G. Numerical study of the energy performance of nanofluids used in secondary loops of refrigeration systems. Int J Refrig 2015; 52:122-32.

14. Vasconcelos AA, Gómez AOC, Filho EPB, Parise JAR. Experimental evaluation of SWCNT-water nanofluid as a secondary fluid in a refrigeration system. Appl Therm Eng 2017; 111:1487-92.

15. Boyaghchi FA, Mahmoodnezhad M, Sabeti V. Exergoeconomic analysis and optimization of a solar-driven dual evaporator vapor compression-absorption cascade refrigeration system using water/CuO nanofluid. J Clean Prod 2016; 139:970-85.

16. Anbu, S., Venkatachalapathy, S., \& Suresh, S. (2019). Convective heat transfer studies on helically corrugated tubes with spiraled rod insert using TiO2/DI water nanofluids. Journal of Thermal Analysis and Calorimetry, 137(3), 849-864. I

17. Rehman, W. U., Merican, Z. M. A., Bhat, A. H., Hoe, B. G., Sulaimon, A. A., Akbarzadeh, O., ... Assiri, M. A. (2019). Synthesis, characterization, stability, and thermal conductivity of multi-walled carbon nanotubes (MWCNTs) and eco-friendly jatropha seed oil-based nanofluid: An experimental investigation and modeling approach. Journal of Molecular Liquids, 293, 111534.

18. Asadi, M., Asadi, A., \& Aberoumand, S. (2018). An experimental and theoretical investigation on the effects of adding hybrid nanoparticles on heat transfer efficiency and pumping power of an oil-based nanofluid as a coolant fluid. International Journal of Refrigeration, 89, 83-92. 
J. Anandakumar et al., International Journal of Emerging Trends in Engineering Research, 9(8), August 2021, 1205 - 1210

19. Arya, H., Sarafraz, M. M., \& Arjomandi, M. (2018). Heat transfer and fluid flow of $\mathrm{MgO} / \mathrm{ethylene}$ glycol in a corrugated heat exchanger. Journal of Mechanical Science and Technology, 32(8), 3975-3982.

20. Zadkhast, M., Toghraie, D., \& Karimipour, A. (2017). Developing a new correlation to estimate the thermal conductivity of MWCNT-CuO/water hybrid nanofluid via an experimental investigation. Journal of Thermal Analysis and Calorimetry, 129(2), 859-867.

21. Kamatchi, R., Venkatachalapathy, S., \& Abhinaya Srinivas, B. (2015). Synthesis, stability, transport properties, and surface wettability of reduced graphene oxide/water nanofluids. International Journal of Thermal Sciences, 97, 17-25.

22. Khoshvaght-Aliabadi, M., \& Hormozi, F. (2015). Heat transfer of Cu-water nanofluid in parallel, corrugated, and strip channels. Journal of Thermophysics and Heat Transfer, 29(4), 747-756.

23. Takabi, B., \& Salehi, S. (2014). Augmentation of the heat transfer performance of a sinusoidal corrugated enclosure by employing hybrid nanofluid. Advances in Mechanical Engineering, 2014.

24. J. Anandakumar, K. Pajaniradja Kichena, Improving Performance of vapour compression refrigeration system by using PCM in evaporator, Jcps. 10 (2017) 1599-1602. www.jchps.com.

25. Anandakumar J, To Conduct The Performance Test On Chiller Unit By Using Nanofluid Cooled Condenser, 2015. www.ijmerr.com.

26. Sergey Mikhailovich Usikov (2020). Simulation of Heat Transfer by Water Heating Convectors. International Journal of Emerging Trends in Engineering Research, 8 (2020) 726-734. 